\title{
Stable tin perovskite solar cells developed via additive engineering
}

\author{
Zhensheng Dai ${ }^{1,2 \dagger}$, Taoyuze $\mathrm{Lv}^{1,2,3 \dagger}$, Julien Barbaud ${ }^{1,2 \dagger}$, Wentao Tang ${ }^{1,2}$, Tao Wang ${ }^{1,2}$, Liang Qiao ${ }^{1,2}$, \\ Han Chen ${ }^{1,2}$, Rongkun Zheng ${ }^{3}$, Xudong Yang ${ }^{1,2^{*}}$ and Liyuan Han ${ }^{1,2}$
}

\begin{abstract}
Tin perovskite solar cells (TPSCs) are promising for lead-free perovskite solar cells (PSCs) and have led to extensive research; however, the poor crystallinity and chemical stability of tin perovskites are two issues that prevent stable TPSCs. In this study, we outline a new process that addresses these issues by using tin(II) acetate $\left(\mathrm{Sn}(\mathrm{Ac})_{2}\right)$ in place of the conventional $\mathrm{SnF}_{2}$ precursor additive. Compared with $\mathrm{SnF}_{2}$, $\mathrm{Sn}(\mathrm{Ac})_{2}$ improves the crystallinity and stability of tin perovskite with fewer defects and better charge extraction. Using this process, we developed a device that has a higher external quantum efficiency for charge extraction compared with the

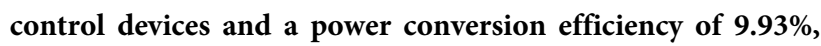
which maintained more than $90 \%$ of its initial efficiency after $1000 \mathrm{~h}$ operation at the maximum power point under standard AM 1.5G solar illumination.
\end{abstract}

Keywords: perovskite solar cells, stability, lead-free perovskite, tin(II) acetate, $\mathrm{FASnI}_{3}$

\section{INTRODUCTION}

Organic-inorganic lead halide perovskite solar cells (PSCs) have been instrumental in converting solar energy into electricity at low cost, and their efficiency has increased from $3.8 \%$ to $25.5 \%$ [1-8]. Improvements in their overall stability have also contributed to lead-based perovskite's success [9-16]; nonetheless, the toxicity of lead remains a concern in the large-scale application of PSCs, and the potential danger of lead poisoning has cast doubts over their future implementation $[17,18]$. Recently, tin PSCs (TPSCs), which are more environmentally friendly, have become the most promising candidates for lead-free
PSCs [19-22]; however, poor crystallinity and the oxidation of $\mathrm{Sn}^{2+}$ to $\mathrm{Sn}^{4+}$ in tin perovskite films remain barriers to their use in efficient and stable solar cells [23].

Various approaches have been used to optimize the crystallinity and stability of tin perovskites. For example, inorganic compounds such as $\mathrm{SnF}_{2}$ or $\mathrm{SnCl}_{2}$ are commonly used to compensate for the oxidized $\mathrm{Sn}^{2+}$ [24-29]. This allows for the reduction of Sn vacancies from $\mathrm{Sn}^{4+}$ to $\mathrm{Sn}^{2+}$ via a comproportionation reaction by metallic tin $[30,31]$. Long-chain ammonium cations such as phenylethylammonium, butylammonium, and ethylammonium have also been used to form two- and three-dimensional hierarchy structures that protect tin perovskites from oxidation and passivate the trap states [32-41]. It has also been reported that the addition of some small organic molecules or polymers, such as trimethylamine [42], $\mathrm{CH}_{3} \mathrm{NH}_{3} \mathrm{I} \cdot 3 \mathrm{CH}_{3} \mathrm{NH}_{2}$ amine complex [43], the potassium salt of hydroquinone sulfonic acid [44], 8-hydroxyquinoline [45], liquid formic acid [46], pentafluorophenoxyethylammonium iodide [47], or poly(vinyl alcohol) [48] can improve the crystallinity and reduce the defects caused by oxidation, thereby enhancing the stability of the resulting tin perovskite. Among these strategies, $\mathrm{SnF}_{2}$ is the most commonly used additive in the fabrication of TPSCs, which, by creating more nucleation sites during the crystallization process, enables the formation of uniform tin perovskite films with high coverage and few defects [49]. This process, however, requires the addition of a relatively large amount ( $10 \%$ or more molar ratio) of $\mathrm{SnF}_{2}$ to achieve the prenucleation effect, although, if $\mathrm{SnF}_{2}$ is applied at a molar ratio higher than $10 \%$, it can also

\footnotetext{
${ }^{1}$ State Key Laboratory of Metal Matrix Composites, School of Materials Science and Engineering, Shanghai Jiao Tong University, Shanghai 200240, China

${ }^{2}$ Joint Research Center for Clean Energy Materials, Shanghai Jiao Tong University, Shanghai 200240, China

${ }^{3}$ School of Physics, Australian Centre for Microscopy \& Microanalysis, Sydney Nano Institute, The University of Sydney, Sydney, NSW 2006, Australia

${ }^{\dagger}$ These authors contributed equally to this work.

* Corresponding author (email: Yang.xudong@sjtu.edu.cn)
} 
aggregate at the surface and insulate the charge extraction effects of TPSCs $[26,50]$. These limitations mean that it is highly desirable to obtain alternative additives to control the crystallization of tin perovskite.

In this study, we propose an innovative alternative additive that removes the need for $\mathrm{SnF}_{2}$ completely. We will demonstrate that tin(II) acetate $\left(\mathrm{Sn}(\mathrm{Ac})_{2}\right)$ is capable of the same benefits of $\mathrm{SnF}_{2}$ with improved overall performance. $\mathrm{Sn}(\mathrm{Ac})_{2}$ can improve the crystallization process more efficiently than $\mathrm{SnF}_{2}$ whilst markedly improving the stability and charge extraction of TPSCs. Through experimental and theoretical arguments, we demonstrate that acetate has the ability to bond to the surface $S n$ atoms and protect them from extrinsic degradation and oxidation, which contributes to a lower defect concentration and sizeable improvement in stability. In addition, charge extraction is facilitated at the interface, which, added to a lower trap state concentration, makes $\mathrm{Sn}(\mathrm{Ac})_{2}$ an excellent additive for high-efficiency tin-based devices. Our target device reached $9.93 \%$ power conversion efficiency (PCE), which could maintain at up to $90 \%$ of its initial efficiency over the course of operation at the maximum power point under AM $1.5 \mathrm{G}\left(100 \mathrm{~mW} \mathrm{~cm}^{-2}\right)$ solar illumination for $1000 \mathrm{~h}$. Considering these qualities, we present a solution for stabilizing tin perovskites through the reduction of detrimental oxidation processes while also offering improved electronic performance compared with the most common alternatives.

\section{EXPERIMENTAL SECTION}

\section{Materials}

The following chemicals were obtained from commercial sources and used as received: poly(3,4-ethylenedioxythiophene)-poly(styrenesulfonate)

(PEDOT:PSS) (AI4083, Heraeus), $\mathrm{SnI}_{2} \quad$ (99.99\%, Sigma-Aldrich), $\mathrm{CH}\left(\mathrm{NH}_{2}\right)_{2} \mathrm{I}$ (FAI) ( $>98 \%$, Tokyo Chemical Industry Co., Japan), $\mathrm{SnF}_{2}$ (>99\%, Sigma-Aldrich), $\mathrm{Sn}(\mathrm{Ac})_{2}$ (>99\%, Sigma-Aldrich), bathocuproine (BCP) (>99\%, Wako), [6,6]-phenyl-C61-butyric acid methyl ester (PCBM) ( $>99 \%$, Lumtec Co.), and dimethyl sulfoxide (DMSO) ( $\geq 99.9 \%$, Sigma-Aldrich).

\section{Solar cell fabrication}

Patterned indium tin oxide (ITO) substrates were cleaned sequentially in detergent, deionized water, acetone, and isopropanol by ultrasonication for $20 \mathrm{~min}$ each and subsequently cleaned with ultraviolet (UV) ozone for 30 min before the deposition of the PEDOT:PSS layer. The perovskite precursor solution was composed of
$1 \mathrm{~mol} \mathrm{~L}^{-1} \mathrm{SnI}_{2}$ and $1 \mathrm{~mol} \mathrm{~L}^{-1} \mathrm{FAI}$ in DMSO and was stirred at room temperature for $5 \mathrm{~h}$. The unfiltered precursor solution was spin-coated on the PEDOT:PSS layer at $1000 \mathrm{r} \mathrm{min}^{-1}$ for $12 \mathrm{~s}$ and $5000 \mathrm{rmin}^{-1}$ for $48 \mathrm{~s}$ in a glovebox. Chlorobenzene $(150 \mu \mathrm{L})$ was dripped onto the perovskite film at $30 \mathrm{~s}$ during the second step. The perovskite films were then annealed at $60^{\circ} \mathrm{C}$ for $10 \mathrm{~s}$ and $100^{\circ} \mathrm{C}$ for $15 \mathrm{~min}$. Two tin perovskite films were fabricated and used as a control $\left(\mathrm{FASnI}_{3}\right.$ with $10 \%$ molar ratio $\left.\mathrm{SnF}_{2}\right)$ and a target $\left(\mathrm{FASnI}_{3}\right.$ with $2 \%$ molar ratio $\left.\mathrm{Sn}(\mathrm{Ac})_{2}\right)$. PCBM (20 mg mL ${ }^{-1}$ in chlorobenzene) solution was spincoated onto the perovskite films at $1000 \mathrm{r} \mathrm{min}^{-1}$ for $60 \mathrm{~s}$ and $5000 \mathrm{r} \mathrm{min}^{-1}$ for $5 \mathrm{~s}$. Finally, $8 \mathrm{~nm} \mathrm{BCP} \mathrm{and} 70 \mathrm{~nm}$ Ag electrode were evaporated under high vacuum $(<2 \times$ $10^{-7}$ Torr, 1 Torr $\left.=1.33322 \times 10^{2} \mathrm{~Pa}\right)$, respectively. The device areas were defined by a mask with an aperture area of $0.09 \mathrm{~cm}^{2}$.

\section{Characterization}

Scanning electron microscopy (SEM) images of the films were captured with a Zeiss Ultra Plus Field Emission Scanning Electron Microscope, and light absorbance spectra were measured with a Shimadzu UV-visible (UVvis) 3600 spectrophotometer. X-ray diffraction (XRD) patterns were obtained with a Bruker D8 ADVANCE DAVINCI diffractometer by $\mathrm{Cu} \mathrm{Ka}$ radiation. X-ray photoelectron spectroscopy (XPS) spectra were obtained with a Kratos Axis UltraDLD using a monochromatic Al $\mathrm{Ka}$ X-ray source with incident and take-off angles of $90^{\circ}$ and $45^{\circ}$, respectively. UV photoelectron spectroscopy (UPS) spectra were also acquired with the Kratos Axis UltraDLD spectrometer but using a monochromatic He I source. Steady-state photoluminescence (PL) and timeresolved PL (TRPL) spectra were obtained using an FLS1000 PL spectrometer with an excitation wavelength of $550 \mathrm{~nm}$. The capacitance-voltage $(C-V)$ was characterized and the dark current curves obtained using a multifunctional electrochemical analysis instrument (Zahner, Germany) under dark conditions at room temperature. The current-voltage $(I-V)$ curves were produced with a solar simulator under standard AM 1.5G sunlight (100 $\mathrm{mW} \mathrm{cm}^{-2}$, WXS-155S-10, Wacom Denso) and forward $(-0.2$ to $0.9 \mathrm{~V})$ or reverse $(0.9$ to $-0.2 \mathrm{~V})$ scanning with a fixed step voltage of $20 \mathrm{mV}$ and delay time of $50 \mathrm{~ms}$. Fourier-transform infrared (FTIR) spectra were obtained with a Bruker VERTEX 70v FT-IR spectrometer. The aperture area was defined with a $0.09-\mathrm{cm}^{2}$ mask. The monochromatic incident photon-to-electron conversion efficiency (IPCE) spectra were measured with a monochromatic incident light of $1 \times 10^{16} \mathrm{~cm}^{-2}$ photons in the 
"director current" mode (CEP2000BX, Bunko-Keiki). The light intensity of the solar simulator was calibrated with a standard silicon solar cell. The TPSC was first encapsulated in cavity glass and UV curable glue in a nitrogen-filled glovebox for the stability test. The thermal stability tests were conducted by heating the control and target films at $85^{\circ} \mathrm{C}$ in an $\mathrm{N}_{2}$ glovebox $\left(100 \mathrm{ppm} \mathrm{O}_{2}\right.$, $10 \mathrm{ppm} \mathrm{H}_{2} \mathrm{O}$ ).

\section{RESULTS AND DISCUSSION}

$\mathrm{SnF}_{2}$ additives have been previously shown to contribute to the formation of heterogeneous nucleation sites by prenucleation to produce dense tin perovskite films $[49,51]$. In our study, the experimental solubility of the $\mathrm{Sn}(\mathrm{Ac})_{2}$ dissolved in DMSO was about $0.018 \mathrm{~mol} \mathrm{~L}^{-1}$ at $25^{\circ} \mathrm{C}$, which is far less than that of $\mathrm{SnF}_{2}\left(0.22 \mathrm{~mol} \mathrm{~L}^{-1}\right)$. Accordingly, the density of heterogeneous nuclei that can be provided during $\mathrm{FASnI}_{3}$ crystal growth was improved, even with comparatively smaller amounts of $\mathrm{Sn}(\mathrm{Ac})_{2}$ than $\mathrm{SnF}_{2}$. Fig. 1a, b show the SEM images of the control $\left(\mathrm{FASnI}_{3}\right.$ with $\left.10 \% \mathrm{SnF}_{2}\right)$ and target $\left(\mathrm{FASnI}_{3}\right.$ with $2 \%$ $\left.\mathrm{Sn}(\mathrm{Ac})_{2}\right)$ films. These images illustrate the dense and uniform structure of both films with a grain size of around $1 \mu \mathrm{m}$, and the light absorbance spectra in Fig. 1c, $d$ show that the target film was more stable than the control film under heat $\left(85^{\circ} \mathrm{C}\right.$ in an $\mathrm{N}_{2}$ glovebox (100 ppm $\left.\mathrm{O}_{2}, 10 \mathrm{ppm} \mathrm{H}_{2} \mathrm{O}\right)$ ). The XRD of the two films were compared (detailed XRD pattern parameters are listed in Table S1), which demonstrated that the target film $\left(2 \% \mathrm{Sn}(\mathrm{Ac})_{2}\right)$ showed superior crystallinity. Fig. 1e, $\mathrm{f}$
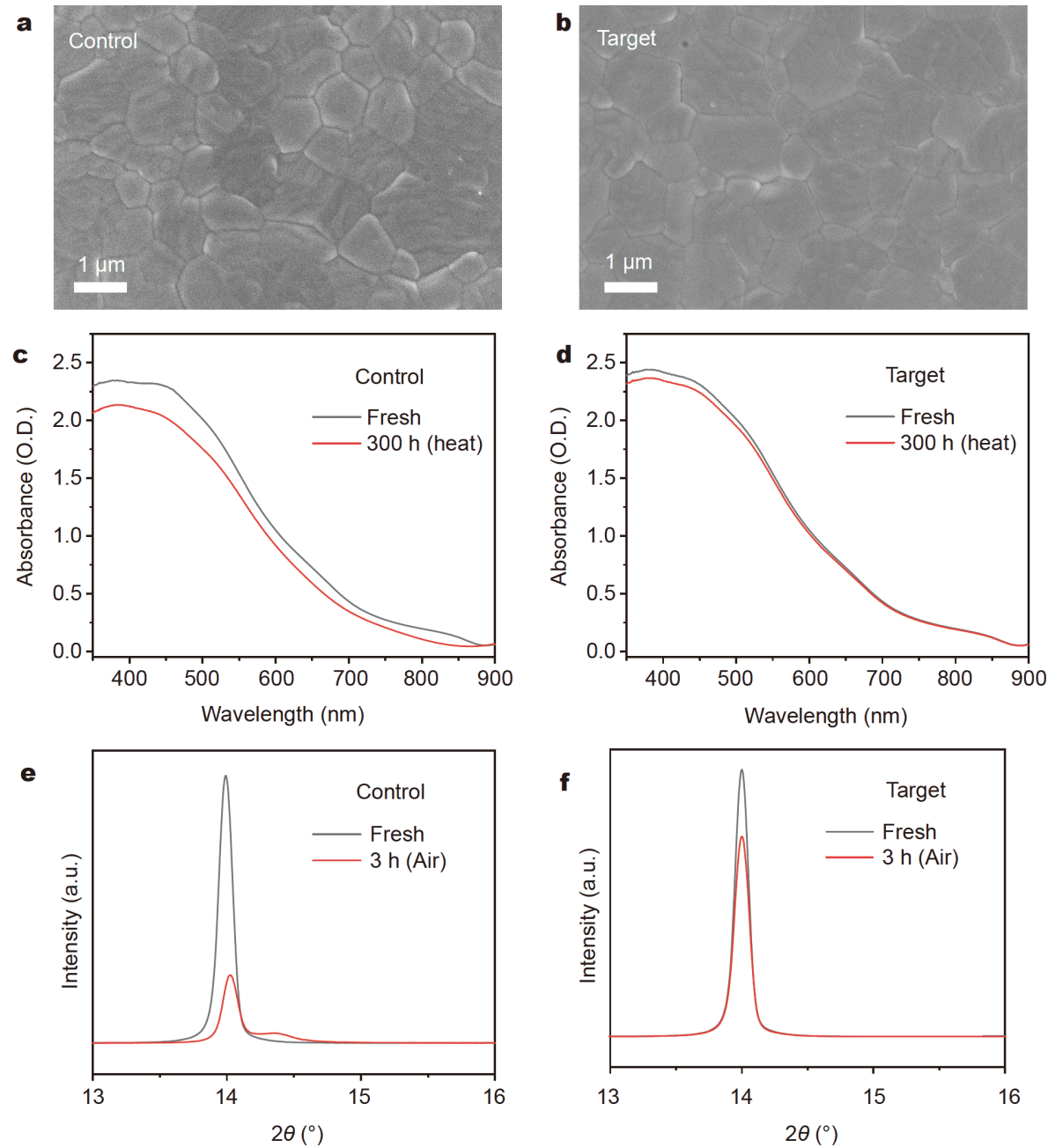

Figure 1 (a, b) SEM images of the control and the target films, respectively, deposited on the ITO/PEDOT:PSS substrates. The scale bar is $1 \mu \mathrm{m}$. (c, d) The light absorbance spectra of the control and target films, respectively, before and after heating at $85^{\circ} \mathrm{C}$ in an $\mathrm{N}_{2}$ glovebox $\left(100 \mathrm{ppm} \mathrm{O}_{2}\right.$, $10 \mathrm{ppm} \mathrm{H}_{2} \mathrm{O}$ ) in the dark. (e, f) Narrow sweep of the XRD patterns between $13^{\circ}$ and $15^{\circ}$ of the control and target films, respectively, deposited on the ITO/PEDOT:PSS substrates after 0 and $3 \mathrm{~h}$ of oxidation in an air environment $\left(25^{\circ} \mathrm{C}, 30 \%\right.$ relative humidity). 
show a comparison of the XRD patterns of a fresh film with a control film that was left to oxidize in air $\left(25^{\circ} \mathrm{C}\right.$, $30 \%$ relative humidity) for $3 \mathrm{~h}$. A new phase appeared in the control film (Fig. 1e) at around $14.5^{\circ}$, which we designated as a previously identified phase originating from the co-existence of $\mathrm{Sn}^{4+}$ and $\mathrm{Sn}^{2+}$ [52,53]; conversely, following $3 \mathrm{~h}$ air exposure, the target film (Fig. 1f) only showed a decrease in (100) intensity with no obvious peak near $14.5^{\circ}$, which indicated that the target film exhibited enhanced stability in air.

We then determined the optimal molar ratio of additive for both $\mathrm{SnF}_{2}$ and $\mathrm{Sn}(\mathrm{Ac})_{2}$. As shown in Fig. S1, the morphology of the film tended to increase in density when the amount of $\mathrm{SnF}_{2}$ was increased from $5 \%$ to $10 \%$; however, when the concentration of $\mathrm{SnF}_{2}$ reached $20 \%$, the grain size became smaller, which is detrimental to TPSC performance. This phenomenon has been previously reported and attributed to the prenucleation of $\mathrm{SnF}_{2}$ [49]. In the corresponding XRD results, the intensity and full width at half maximum (FHWM) of the (100) peak in Fig. S2 also revealed that the best molar ratio of $\mathrm{SnF}_{2}$ was $10 \%$. We then repeated these tests to determine the optimal molar ratio of $\mathrm{Sn}(\mathrm{Ac})_{2}$, which, as shown in the SEM images in Fig. S3, was found to be $2 \%$. This concentration allowed a uniform and dense morphology with the largest grain size, and the result was verified by the XRD results, as shown in Fig. S4.

To further understand the mechanism that resulted in the improved stability when using $\operatorname{Sn}(\mathrm{Ac})_{2}$, we used PL measurements as a more sensitive assessment of the changes in the control and target films after the heating test $\left(85^{\circ} \mathrm{C}\right.$ in the $\mathrm{N}_{2}$ glovebox $\left(100 \mathrm{ppm} \mathrm{O}_{2}, 10 \mathrm{ppm} \mathrm{H}_{2} \mathrm{O}\right)$. Fig. S5a shows the markedly reduced PL intensity attenuation of the target film compared with the control (Fig. S5b). We assumed that this could be due to the passivating role of acetate on the under-coordinated surface Sn atoms [54,55], as illustrated in Fig. 2a. To verify this, we performed the thermal stability test and compared the $\mathrm{FASnI}_{3}$ films with no other additives or with only $2 \%$ formamidine acetate (FAAc). The light absorbance and PL spectra in Fig. S6a-d show that the $\mathrm{FASnI}_{3}$ films prepared by adding acetate had better stability, which demonstrated that the acetate was able to stabilize the $\mathrm{FASnI}_{3}$ on its own. We then characterized the FAAc powder and FAAc/SnI ${ }_{2}$ mixed powder through their FTIR spectra (Fig. 2b) to examine the coordination of acetate and $\mathrm{Sn}^{2+}$. It is possible that the oxygen in acetate could form hydrogen bonds with the amino groups of the FA cations, resulting in a broadening effect of amino-group vibration peak $\left(2200-3700 \mathrm{~cm}^{-1}\right)$ towards a smaller wavelength $\left(3300 \mathrm{~cm}^{-1}\right)$; however, when mixing FAAc and $\mathrm{SnI}_{2}$, the hydrogen bond is weakened and breaks as acetate is more favorable to coordinating with $\mathrm{Sn}^{2+}$, which is indicated by the narrowed amino peak and carboxyl peak shift from 1720 to $1713 \mathrm{~cm}^{-1}$ in the FTIR spectra. This phenomenon indicates that the carboxyl group of the acetate anion is able to coordinate strongly with a Sn cation, thereby passivating the defects of undercoordinated Sn on the film surface.

Density functional theory (DFT) calculations conducted on the bare $\mathrm{FASnI}_{3}$ and the acetate-covered surface validated our other experimental results and provided some explanation regarding the improved stability of the films. The adsorption energy of acetate on top of a Sn-I terminated surface is $1.84 \mathrm{eV}$ per molecule, which, since this energy is more than an order of magnitude greater than the thermal energy of a molecule at room temperature (obtained as $3 / 2 k_{\mathrm{b}} T=3.9 \times 10^{-2} \mathrm{eV}$ ), indicates a strong attraction of the acetate to the surface Sn atoms; the strongly electron-accepting carboxyl group of the acetate readily accepts electrons from the surface $\mathrm{Sn}$, thereby bonding it. We also noticed that extrinsic stability was improved through the surface passivation by acetate, which provided a protective layer against external foreign species. The acetate additive also appeared to reduce the surface polarity in our simulations, which resulted in fewer attractive sites for polar molecules such as $\mathrm{H}_{2} \mathrm{O}$. Fig. S7b is a visualization of this reduced polarity, which plots the total potential obtained from DFT simulations as a color map on top of the charge density isosurfaces. This demonstrated that the acetate molecules adsorbed on the $\mathrm{FASnI}_{3}$ surface exhibited a much weaker polarization than the bare $\mathrm{Sn}$ atoms on the surface (colored in blue in Fig. S7b); conversely, our computations of the polarity of an F-covered $\mathrm{FASnI}_{3}$ surface (Fig. S7a), resulting from the use of a $\mathrm{SnF}_{2}$ additive, indicated that the exposed surface $\mathrm{F}$ atom offered greater electrostatic potential, which favors polar interactions.

We then performed a Bader charge analysis of the surface to quantify its polarization: the surface $\mathrm{Sn}$ atoms had an average atomic Bader charge of $+1.05 \mathrm{e}$, the exposed group of the acetate had a charge of $-0.17 \mathrm{e}$, and the $\mathrm{F}$ had a charge of $-1.01 \mathrm{e}$. These lowered charges indicate the difference in the passivation strategy between $\mathrm{SnF}_{2}$ and $\mathrm{Sn}(\mathrm{Ac})_{2}$ additives; the acetate coverage greatly reduces the exposed surface polarity, while the fluoride additives create significant dipolar moments on the surface instead. The negatively charged acetate carboxyl group ensures the strong binding of the acetate group to the under-coordinated $\mathrm{Sn}^{2+}$ ions, which is verified by the 

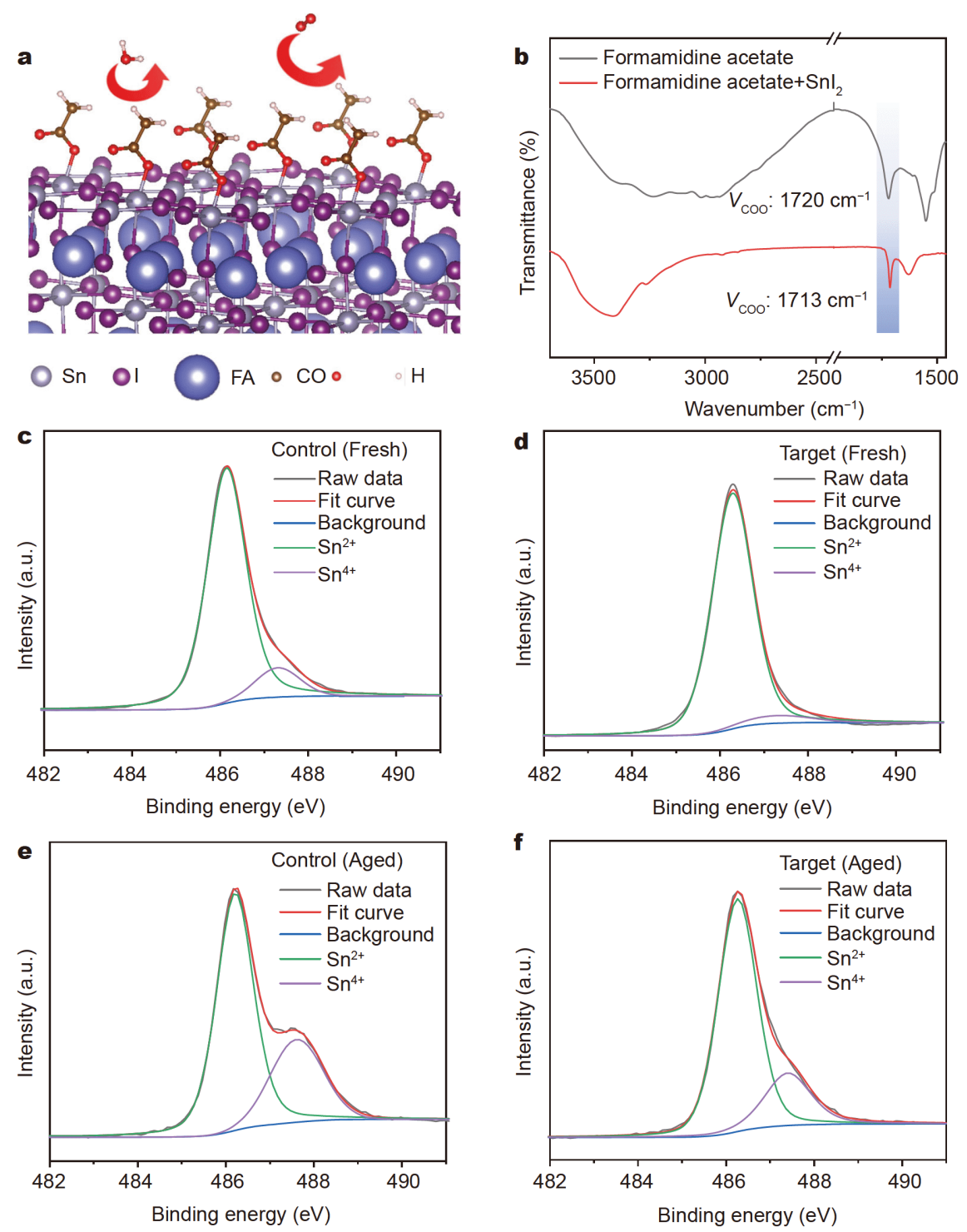

Figure 2 (a) A schematic representation of the role of acetate passivation in the extrinsic stability of FASnI $\mathrm{F}_{3}$. (b) FTIR spectra of FAAc and the complex of FAAc and $\mathrm{SnI}_{2}$. (c, d) Sn 3d XPS spectra of the fresh control and target films, respectively, with their $\mathrm{Sn}^{4+}$ contents calculated as $10.68 \%$ and $5.02 \%$, respectively. (e, f) Sn $3 \mathrm{~d}$ XPS spectra of the control and target films exposed in air $\left(25^{\circ} \mathrm{C}, 30 \%\right.$ relative humidity) for $3 \mathrm{~h}$, respectively, with their $\mathrm{Sn}^{4+}$ contents calculated as $55.08 \%$ and $29.75 \%$, respectively.

high adsorption energy in our simulation, while the weakly polarized characteristic of the exposed nonbonding termination minimizes the electrostatic attraction of foreign polar molecules (e.g., $\mathrm{H}_{2} \mathrm{O}$ and $\mathrm{O}_{2}$ ). We therefore propose that the acetate-covered layer has a screening effect with the exposed non-bonding termination of the acetate group acting as a quasi-neutral barrier on top of the polar groups and surface atomic charges, which increases the stability of tin perovskite under ambient conditions.

This mechanism also allows the further stabilization against oxygen exposure by covering the easily oxidized surface $\mathrm{Sn}$ atoms with a much less reactive termination; therefore, we showed that the extrinsic stability against oxygen and water could be improved by covering the surface with acetate as a protective barrier, as illustrated in Fig. 2a.

We then further characterized the stability of the control and target films after oxidation in air for $3 \mathrm{~h}$ (Fig. 2c-f) using XPS to detect the $\mathrm{Sn}^{4+}$ and $\mathrm{Sn}^{2+}$ contents of the films. The XPS measurement chamber was disassembled and reassembled inside the glovebox to allow 
for sample loading without air exposure. The $\mathrm{Sn}^{4+}$ content on the control film was about $11 \%$, while the $\mathrm{Sn}^{4+}$ content on the target film was only about $5 \%$, which may be due to the acetate stabilizing the surface during fabrication and testing. Following oxidation in air for $3 \mathrm{~h}\left(25^{\circ} \mathrm{C}, 20 \%\right.$ relative humidity), the $\mathrm{Sn}^{2+}$ content at the surface decreased to about $45 \%$ on the control film (Fig. 2e), whereas the majority of the $\mathrm{Sn}^{2+}(>70 \%)$ remained on the target film surface (Fig. 2f). By etching the films with an $\mathrm{Ar}$ ion beam, we were then able to determine the content of $\mathrm{Sn}^{2+}$ at varying depths in the film. The $\mathrm{Sn}^{2+}$ content was better preserved in the target film compared with the control film (Fig. S8), further indicating that it had improved protection from oxidation. We also measured the contact angle (Fig. S9) and found that the target film with $\mathrm{Sn}(\mathrm{Ac})_{2}$ also had improved resistance to water. These results both verified our simulation results.

We then measured the energy levels of the control and target films with UPS. The control film had a Fermi level of $-4.45 \mathrm{eV}$, a valence band minimum (Fig. S10a, b) of $-5.13 \mathrm{eV}$, and, with an optical bandgap of $1.38 \mathrm{eV}$ from the Tauc plots (Fig. S11), the conduction band maximum of the control film was calculated to be $-3.75 \mathrm{eV}$. The target film had a Fermi level of $-4.42 \mathrm{eV}$, a valence band minimum (Fig. S12a, b) of $-5.12 \mathrm{eV}$, and, with an optical bandgap of $1.38 \mathrm{eV}$ from the Tauc plots (Fig. S13), the conduction band maximum of the target film was calculated to be $-3.74 \mathrm{eV}$. The small shift of the valence band was attributed to a smaller degree of oxidation of the surface Sn, which verified the XPS result and that acetate can stabilize the surface of $\mathrm{FASnI}_{3}[56,57]$.

We then characterized the defects and charge transport capabilities of the films through PL and carrier lifetime measurements. The PL spectra of the glass/FASnI $3^{-}$ control and glass/FASnI ${ }_{3}$-control/PCBM, and glass/ FASnI $_{3}$-target and glass/FASnI ${ }_{3}$-target/PCBM architectures were measured, which, as shown in Fig. 3a, indicated an increase in PL intensity for the target film compared with the control film. This is consistent with our TRPL measurements (Fig. 3b), which showed that the target sample had a longer carrier lifetime $(9.8 \mathrm{~ns})$ than the control sample $(4.1 \mathrm{~ns})$. These results both indicated a reduction in the amount of non-radiative recombination centers in the target film. We further characterized the PL
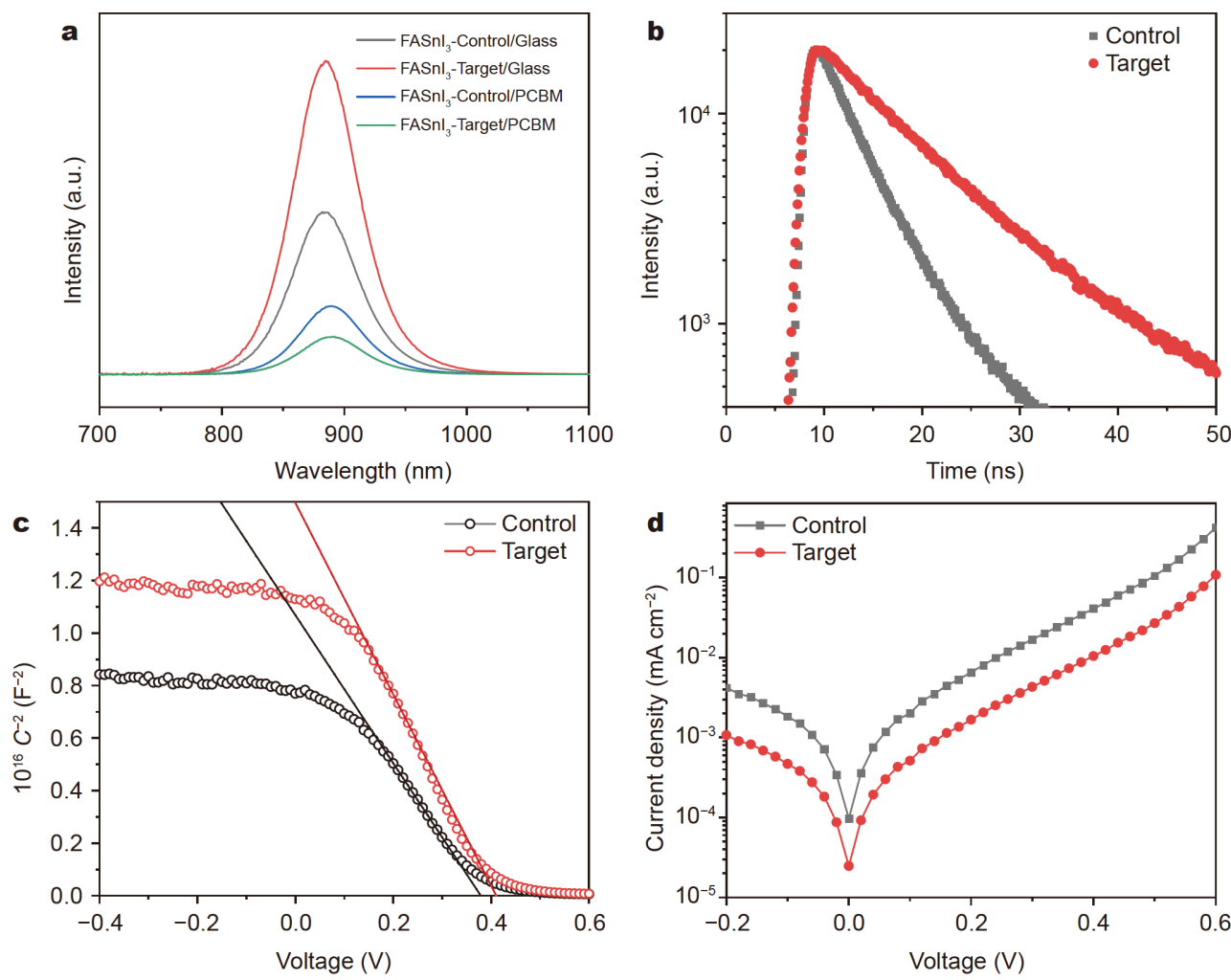

Figure 3 (a) Steady-state PL spectra of the control and target films on the glass and ITO/PCBM substrates. (b) TRPL spectra of the control and

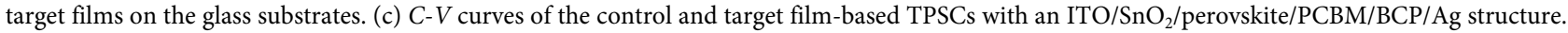
(d) Dark current curves of the devices with an $\mathrm{ITO} / \mathrm{SnO}_{2} /$ perovskite/PCBM/BCP/Ag structure. 
quenching induced by charge separation at the interface between $\mathrm{FASnI}_{3}$ and PCBM films. The PL quenching of the $\mathrm{FASnI}_{3}$-target/PCBM film was about $90 \%$, which, compared with $50 \%$ for the $\mathrm{FASnI}_{3}$-control/PCBM film, indicated a more efficient interfacial charge separation at the interface of the $\mathrm{FASnI}_{3}$-target/PCBM film.

Fig. $3 c$ shows our $C-V$ characterization using the MottSchottky Equation (1) to determine the carrier density $\left(N_{\mathrm{a}}\right)$ [53]:

$N_{\mathrm{a}}=-\frac{2}{q \varepsilon_{0} \varepsilon A^{2}} \times\left[\frac{\mathrm{d}}{\mathrm{d} V}\left(\frac{1}{C^{2}}\right)\right]^{-1}$

where $q$ is the elemental charge, $\varepsilon_{0}$ is the permittivity of free space, $\varepsilon$ is the dielectric constant of the absorber layer [37], $A$ is the aperture area of the device, and $C$ is the capacitance. The calculated defect density of the target film-based device was $8.10 \times 10^{16} \mathrm{~cm}^{-3}$, which is much lower than that of the control film-based device $(1.08 \times$ $\left.10^{17} \mathrm{~cm}^{-3}\right)$. This reduced defect concentration can be attributed to the suppressed $\mathrm{Sn}^{2+}$ oxidation in the target film-based device, which confirmed the previous stability test result. The dark currents for the corresponding devices are shown in Fig. 3d, with the current leakage of the target film-based device being four times lower than that of the control film-based device, which indicated a more efficient collection of photo-generated carriers in the target film-based device.

We then fabricated solar cells with an ITO/PEDOT: $\mathrm{PSS} /$ perovskite/PCBM/BCP/Ag structure and fabricated 24 control and 24 target film-based devices. Using these, we determined their PCEs, which were $5.98 \%$ and $9.93 \%$, respectively (Fig. 4c). The forward and reverse scans of the $I$ - $V$ curves are shown in Fig. $4 \mathrm{a}$, and the details of the open-circuit voltage $\left(V_{\mathrm{OC}}\right)$, short-circuit current density $\left(J_{\mathrm{SC}}\right)$, and fill factor $(\mathrm{FF})$ are listed in Table S2. The hysteresis effect was suppressed in the target film-based PSCs, which could be due to the reduced trap density [46]. The integrated current densities for the control and target devices were calculated to be 14.97 and $20.40 \mathrm{~mA} \mathrm{~cm}^{-2}$, respectively, from their IPCE spectra (Fig. 4b), which are consistent with the $J_{\mathrm{SC}}$ determined from $I-V$ curves. The elevated IPCE spectrum indicated that the target film-based devices could extract charge carriers more efficiently than the control film-based devices.

Finally, we investigated the operational stability of the two sets of solar cells in the air $\left(25^{\circ} \mathrm{C}\right.$, relative humidity 20\%-25\%). The encapsulated target film-based solar cell maintained over $93 \%$ of its initial efficiency after operating at maximum power point tracking under simulated
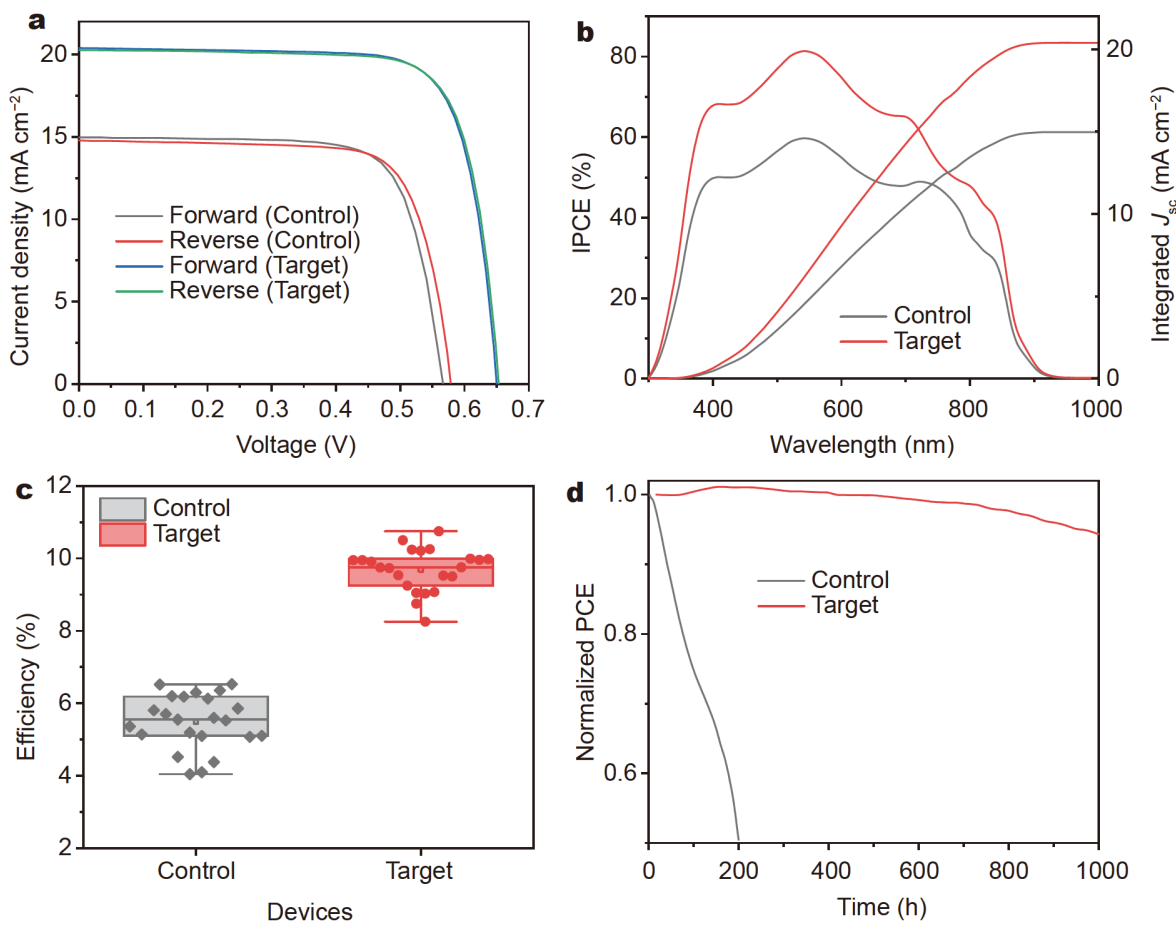

Figure 4 (a) $I$ - $V$ curves for the control and target film-based devices. (b) IPCE spectra for the control and target film-based devices. (c) The box plot chart for the distributions of PCEs measured for the control and target film-based devices (24 of each). (d) The stability test of encapsulated TPSCs under simulated AM $1.5 \mathrm{G}\left(100 \mathrm{~mW} \mathrm{~cm}^{-2}\right)$ illumination at their maximum power point in air $\left(25^{\circ} \mathrm{C}\right.$, relative humidity $\left.20 \%-25 \%\right)$. 
AM 1.5G $\left(100 \mathrm{~mW} \mathrm{~cm}^{-2}\right)$ illumination for $1000 \mathrm{~h}$ (red line in Fig. 4d); conversely, under the same conditions, the control film-based device lost almost $50 \%$ of its initial efficiency within $200 \mathrm{~h}$ (black line in Fig. 4d). These stability results were consistent with our previous findings.

\section{CONCLUSIONS}

In summary, we present a strategy to improve the crystallinity and stability of $\mathrm{FASnI}_{3}$ perovskite by using $\mathrm{Sn}(\mathrm{Ac})_{2}$ as a precursor additive, which is demonstrated through multiple procedures to be an attractive replacement for the commonly used $\mathrm{SnF}_{2}$ precursor additive. SEM and XRD characterizations demonstrated the superior crystallinity of our target samples, and a clear increase in stability was observed through the results of several experimental methods, including their absorbance spectra, PL, XRD, and XPS. FTIR spectra and theoretical calculations allowed us to attribute these improved qualities to the strong binding of acetate to undercoordinated Sn atoms, which creates a weakly polarized protective layer that reduces extrinsic degradation. Compared with the films produced with a $\mathrm{SnF}_{2}$ additive, our target films exhibited reduced defect density, which was calculated through $C$ - $V$ measurements, and enhanced charge extraction at the interface with PCBM, which was evidenced through TRPL characterization. The TPSC is remarkably efficient and stable based on our novel acetate strategy, which yields a PCE of $9.93 \%$ maintained to $90 \%$ over the course of $1000 \mathrm{~h}$ under standard illumination. In conclusion of these findings, we propose $\mathrm{Sn}(\mathrm{Ac})_{2}$ to be a beneficial replacement to the commonly used $\mathrm{SnF}_{2}$ additive which achieves better qualities. This new stabilization strategy is an important step towards efficient, lead-free PSCs.

Received 6 February 2021; accepted 18 March 2021; published online 20 May 2021

1 Kojima A, Teshima K, Shirai Y, et al. Organometal halide perovskites as visible-light sensitizers for photovoltaic cells. J Am Chem Soc, 2009, 131: 6050-6051

2 Kim HS, Lee CR, Im JH, et al. Lead iodide perovskite sensitized allsolid-state submicron thin film mesoscopic solar cell with efficiency exceeding 9\%. Sci Rep, 2012, 2: 591

3 Yang WS, Park BW, Jung EH, et al. Iodide management in formamidinium-lead-halide-based perovskite layers for efficient solar cells. Science, 2017, 356: 1376-1379

4 Jiang Q, Zhao Y, Zhang X, et al. Surface passivation of perovskite film for efficient solar cells. Nat Photonics, 2019, 13: 460-466

5 Jung EH, Jeon NJ, Park EY, et al. Efficient, stable and scalable perovskite solar cells using poly(3-hexylthiophene). Nature, 2019, 567: 511-515
6 Chen $\mathrm{W}, \mathrm{Wu} \mathrm{Y}$, Yue Y, et al. Efficient and stable large-area perovskite solar cells with inorganic charge extraction layers. Science, 2015, 350: 944-948

7 Best research-cell efficiency chart. https://www.nrel.gov/pv/cellefficiency.html

8 Wang $\mathrm{Y}$, Wang $\mathrm{H}$, Chen $\mathrm{M}$, et al. Bilayer broadband antireflective coating to achieve planar heterojunction perovskite solar cells with 23.9\% efficiency. Sci China Mater, 2021, 64: 789-797

9 Song W, Cao G. Surface-defect passivation through complexation with organic molecules leads to enhanced power conversion efficiency and long term stability of perovskite photovoltaics. Sci China Mater, 2020, 63: 479-480

10 Wu YH, Ding Y, Liu XY, et al. Ambient stable $\mathrm{FAPbI}_{3}$-based perovskite solar cells with a $2 \mathrm{D}-\mathrm{EDAPbI}_{4}$ thin capping layer. Sci China Mater, 2020, 63: 47-54

11 Yang S, Chen S, Mosconi E, et al. Stabilizing halide perovskite surfaces for solar cell operation with wide-bandgap lead oxysalts. Science, 2019, 365: 473-478

12 Bai S, Da P, Li C, et al. Planar perovskite solar cells with long-term stability using ionic liquid additives. Nature, 2019, 571: 245-250

13 Wang Y, Dar MI, Ono LK, et al. Thermodynamically stabilized $\beta$ $\mathrm{CsPbI}_{3}$-based perovskite solar cells with efficiencies $>18 \%$. Science, 2019, 365: 591-595

14 Wang Y, Wu T, Barbaud J, et al. Stabilizing heterostructures of soft perovskite semiconductors. Science, 2019, 365: 687-691

15 Zhu Z, Su W, Feng J, et al. Phase degradation of all-inorganic perovskite $\mathrm{CsPb}_{2} \mathrm{Br}$ films induced by a p-type $\mathrm{CuI}$ granular capping layer. Sci China Mater, 2020, 63: 2487-2496

16 Ren $\mathrm{Y}$, Zhang N, Wang Q, et al. Restricting $\delta$-phase transformation of $\mathrm{HC}\left(\mathrm{NH}_{2}\right)_{2} \mathrm{PbI}_{3}$ via iodine-vacancy filling for efficient perovskite solar cells. Sci China Mater, 2020, 63: 1015-1023

17 Abate A. Perovskite solar cells go lead free. Joule, 2017, 1: 659-664

18 Conings B, Babayigit A, Boyen HG. Fire safety of lead halide perovskite photovoltaics. ACS Energy Lett, 2019, 4: 873-878

19 Ju MG, Chen M, Zhou Y, et al. Toward eco-friendly and stable perovskite materials for photovoltaics. Joule, 2018, 2: 1231-1241

20 Wang Y, Yang D, Ma D, et al. Organic-inorganic hybrid Sn-based perovskite photodetectors with high external quantum efficiencies and wide spectral responses from 300 to $1000 \mathrm{~nm}$. Sci China Mater, 2019, 62: 790-796

21 Wang C, Gu F, Zhao Z, et al. Self-repairing tin-based perovskite solar cells with a breakthrough efficiency over $11 \%$. Adv Mater, 2020, 32: 1907623

22 Zhao Z, Gu F, Li Y, et al. Mixed-organic-cation tin iodide for leadfree perovskite solar cells with an efficiency of $8.12 \%$. Adv Sci, 2017, 4: 1700204

23 Zhu T, Yang Y, Gong X. Recent advancements and challenges for low-toxicity perovskite materials. ACS Appl Mater Interfaces, 2020, 12: 26776-26811

24 Gupta S, Cahen D, Hodes G. How $\mathrm{SnF}_{2}$ impacts the material properties of lead-free tin perovskites. J Phys Chem C, 2018, 122: 13926-13936

25 Lee SJ, Shin SS, Im J, et al. Reducing carrier density in formamidinium tin perovskites and its beneficial effects on stability and efficiency of perovskite solar cells. ACS Energy Lett, 2018, 3: 46-53

26 Lee SJ, Shin SS, Kim YC, et al. Fabrication of efficient formamidinium tin iodide perovskite solar cells through $\mathrm{SnF}_{2}$-pyrazine complex. J Am Chem Soc, 2016, 138: 3974-3977

27 Liu X, Wang Y, Wu T, et al. Efficient and stable tin perovskite solar 
cells enabled by amorphous-polycrystalline structure. Nat Commun, 2020, 11: 2678

$28 \mathrm{Yu} \mathrm{BB}, \mathrm{Xu} \mathrm{L}$, Liao M, et al. Synergy effect of both 2,2,2-trifluoroethylamine hydrochloride and $\mathrm{SnF}_{2}$ for highly stable FASnI $_{3-x} \mathrm{Cl}_{x}$ perovskite solar cells. Sol RRL, 2019, 3: 1800290

$29 \mathrm{Gu} \mathrm{F}$, Ye S, Zhao Z, et al. Improving performance of lead-free formamidinium tin triiodide perovskite solar cells by tin source purification. Sol RRL, 2018, 2: 1800136

30 Lin R, Xiao K, Qin Z, et al. Monolithic all-perovskite tandem solar cells with $24.8 \%$ efficiency exploiting comproportionation to suppress $\mathrm{Sn}(\mathrm{II})$ oxidation in precursor ink. Nat Energy, 2019, 4: 864873

31 Nakamura T, Yakumaru S, Truong MA, et al. Sn(IV)-free tin perovskite films realized by in situ $\mathrm{Sn}(0)$ nanoparticle treatment of the precursor solution. Nat Commun, 2020, 11: 3008

32 Wang $\mathrm{F}$, Jiang $\mathrm{X}$, Chen $\mathrm{H}$, et al. 2D-quasi-2D-3D hierarchy structure for tin perovskite solar cells with enhanced efficiency and stability. Joule, 2018, 2: 2732-2743

33 Jokar E, Chien CH, Fathi A, et al. Slow surface passivation and crystal relaxation with additives to improve device performance and durability for tin-based perovskite solar cells. Energy Environ Sci, 2018, 11: 2353-2362

34 Cao DH, Stoumpos CC, Yokoyama T, et al. Thin films and solar cells based on semiconducting two-dimensional Ruddlesden-Popper $\left(\mathrm{CH}_{3}\left(\mathrm{CH}_{2}\right)_{3} \mathrm{NH}_{3}\right)_{2}\left(\mathrm{CH}_{3} \mathrm{NH}_{3}\right)_{n-1} \mathrm{Sn}_{n} \mathrm{I}_{3 n+1}$ perovskites. ACS Energy Lett, 2017, 2: 982-990

35 Liao M, Yu BB, Jin Z, et al. Efficient and stable $\mathrm{FASnI}_{3}$ perovskite solar cells with effective interface modulation by low-dimensional perovskite layer. ChemSusChem, 2019, 12: 5007-5014

36 Shao S, Liu J, Portale G, et al. Highly reproducible Sn-based hybrid perovskite solar cells with 9\% efficiency. Adv Energy Mater, 2018, 8: 1702019

37 Ran C, Gao W, Li J, et al. Conjugated organic cations enable efficient self-healing $\mathrm{FASnI}_{3}$ solar cells. Joule, 2019, 3: 3072-3087

$38 \mathrm{Yu}$ B, Liao M, Zhu Y, et al. Oriented crystallization of mixed-cation tin halides for highly efficient and stable lead-free perovskite solar cells. Adv Funct Mater, 2020, 30: 2002230

39 Liao Y, Liu H, Zhou W, et al. Highly oriented low-dimensional tin halide perovskites with enhanced stability and photovoltaic performance. J Am Chem Soc, 2017, 139: 6693-6699

40 Zhao Z, Gu F, Wang C, et al. Orientation regulation of photoactive layer in tin-based perovskite solar cells with allylammonium cations. Sol RRL, 2020, 4: 2000315

41 Ma S, Cai M, Cheng T, et al. Two-dimensional organic-inorganic hybrid perovskite: From material properties to device applications. Sci China Mater, 2018, 61: 1257-1277

42 Zhu Z, Chueh CC, Li N, et al. Realizing efficient lead-free formamidinium tin triiodide perovskite solar cells via a sequential deposition route. Adv Mater, 2018, 30: 1703800

43 Dai Z, Tang W, Wang T, et al. Stable tin perovskite solar cells enabled by widening the time window for crystallization. Sci China Mater, 2021, 64: 1849-1857

44 Tai Q, Guo X, Tang G, et al. Antioxidant grain passivation for airstable tin-based perovskite solar cells. Angew Chem Int Ed, 2019, 58: $806-810$

45 Lin Z, Liu C, Liu G, et al. Preparation of efficient inverted tinbased perovskite solar cells via the bidentate coordination effect of 8-hydroxyquinoline. Chem Commun, 2020, 56: 4007-4010

46 Meng $\mathrm{X}, \mathrm{Wu} \mathrm{T}$, Liu $\mathrm{X}$, et al. Highly reproducible and efficient $\mathrm{FASnI}_{3}$ perovskite solar cells fabricated with volatilizable reducing solvent. J Phys Chem Lett, 2020, 11: 2965-2971

47 Meng X, Wang Y, Lin J, et al. Surface-controlled oriented growth of $\mathrm{FASnI}_{3}$ crystals for efficient lead-free perovskite solar cells. Joule, 2020, 4: 902-912

48 Meng X, Lin J, Liu X, et al. Highly stable and efficient FASnI $_{3}-$ based perovskite solar cells by introducing hydrogen bonding. Adv Mater, 2019, 31: 1903721

49 Xiao M, Gu S, Zhu P, et al. Tin-based perovskite with improved coverage and crystallinity through tin-fluoride-assisted heterogeneous nucleation. Adv Opt Mater, 2018, 6: 1700615

50 Liao W, Zhao D, Yu Y, et al. Lead-free inverted planar formamidinium tin triiodide perovskite solar cells achieving power conversion efficiencies up to $6.22 \%$. Adv Mater, 2016, 28: $9333-$ 9340

51 Abdel-Shakour M, Chowdhury TH, Matsuishi K, et al. High-efficiency tin halide perovskite solar cells: The chemistry of tin(II) compounds and their interaction with Lewis base additives during perovskite film formation. Sol RRL, 2020, 5: 2000606

52 Wang F, Ma J, Xie F, et al. Organic cation-dependent degradation mechanism of organotin halide perovskites. Adv Funct Mater, 2016, 26: 3417-3423

53 Liu X, Wu T, Chen JY, et al. Templated growth of $\mathrm{FASnI}_{3}$ crystals for efficient tin perovskite solar cells. Energy Environ Sci, 2020, 13: 2896-2902

54 Ricciarelli D, Meggiolaro D, Ambrosio F, et al. Instability of tin iodide perovskites: Bulk p-doping versus surface tin oxidation. ACS Energy Lett, 2020, 5: 2787-2795

55 Kayesh ME, Matsuishi K, Kaneko R, et al. Coadditive engineering with 5-ammonium valeric acid iodide for efficient and stable $\mathrm{Sn}$ perovskite solar cells. ACS Energy Lett, 2019, 4: 278-284

56 Jiang X, Wang F, Wei Q, et al. Ultra-high open-circuit voltage of tin perovskite solar cells via an electron transporting layer design. Nat Commun, 2020, 11: 1245

57 Chen $\mathrm{H}$, Peng $\mathrm{Z}$, Xu K, et al. Band alignment towards high-efficiency $\mathrm{NiO}_{x}$-based $\mathrm{Sn}-\mathrm{Pb}$ mixed perovskite solar cells. Sci China Mater, 2021, 64: 537-546

Acknowledgements This work was supported by the National Natural Science Foundation of China (11834011 and 11911530142). We thank the discussion about the XPS data reduction with Ms. Limin Sun and Ms. Xue Ding (the Instrumental Analysis Center of Shanghai Jiao Tong University). We are grateful for the guidance and verification in device preparations and characterizations by Xiao Liu.

Author contributions Yang X conducted the research project. Dai Z and Yang X conceived the idea. Dai Z, Lv T and Barbaud J carried out the fabrications and characterizations of materials and devices. Barbaud J and Dai Z carried out the DFT calculations and analyses. Tang W, Wang $\mathrm{T}$, Qiao $\mathrm{L}$, Zheng $\mathrm{R}$ and Chen $\mathrm{H}$ were involved in the data analyses. Dai Z, Lv T, Barbaud J and Yang X wrote the manuscript. Yang $\mathrm{X}$, Zheng $\mathrm{R}$ and Han $\mathrm{L}$ revised the manuscript. All authors discussed and reviewed the final manuscript.

Conflict of interest The authors declare that they have no conflict of interest.

Supplementary information online version of the paper.
Supporting data are available in the 


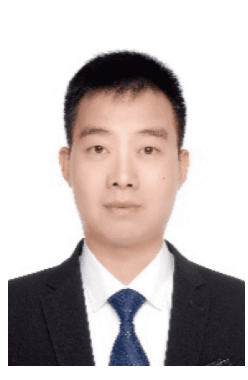

Zhensheng Dai is currently a $\mathrm{PhD}$ candidate at the School of Materials Science and Engineering, Shanghai Jiao Tong University. He received his BS degree from the School of Materials Science and Engineering, Wuhan University of Technology, in 2016. His research focuses on highly efficient and stable perovskite solar cells.

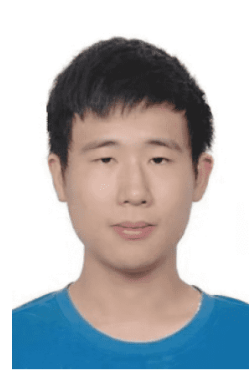

Taoyuze Lv is a PhD student at the School of Physics, the University of Sydney, Australia. He received his bachelor's degree in 2020 from Shenzhen University. His current research interest is the micro-scale simulation and characterization of the physical properties of perovskite materials.

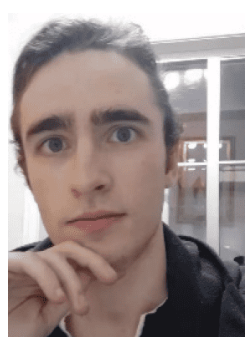

Julien Barbaud is a PhD student at the School of Materials Science and Engineering, Shanghai Jiao Tong University. He obtained his master's degree in 2017 at l'Ecole des Mines d'Albi, France. His current research interest revolves around numerical simulation of materials applied to perovskite-based photovoltaic devices.

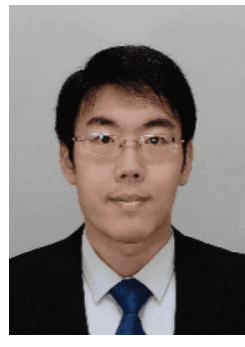

Xudong Yang received his $\mathrm{PhD}$ degree from the Chinese Academy of Sciences. He did postdoctoral research at the University of Cambridge, $\mathrm{UK}$ and the International Center for Young Scientists of the National Institute for Materials Science, Japan. He joined Shanghai Jiao Tong University as a distinguished researcher in 2014. His current research is focused on understanding the mechanisms of the photoelectron conversion, charge transport, and the fabrication of nextgeneration optoelectronic devices for applications in energy conversion.

\section{通过添加剂工程获得稳定的锡基钻铁矿太阳能电池}

戴瑧盛 ${ }^{1,2 \dagger}$, 吕陶玉朢 ${ }^{1,2,3 \dagger}$, 巴尔博. 朱利安 ${ }^{1,2 \dagger}$, 唐文涛 ${ }^{1,2}$, 王涛 ${ }^{1,2}$, 乔亮 ${ }^{1,2}$, 陈汉 ${ }^{1,2}$, 郑荣坤 ${ }^{3}$, 杨旭东 ${ }^{1,2^{*}}$, 韩礼元 ${ }^{1,2}$

摘要 锡基钲铁矿太阳能电池(TPSCs) 是最具有应用前景的无铅钙 钛矿太阳能电池(PSC)之一. 然而, 锡基钻铁矿结晶性差和化学不稳 定性制约了其进一步应用. 在这里, 我们提出了一种新策略, 通过使 用乙酸锡(II)来替代传统的 $\mathrm{SnF}_{2}$ 作为前驱体添加剂来解决上述两个 问题. 与 $\mathrm{SnF}_{2}$ 相比, 乙酸锡( II)添加剂所制备的锡基钙钛矿薄膜具有 更好的结晶性、更高的稳定性、更低的缺陷浓度, 同时能够在光 伏器件中实现更有效的电荷提取. 基于乙酸锡(II)添加剂制备的锡 基钙钛矿太阳能电池实现了 $9.93 \%$ 的光电转换效率(PCE), 在标准 AM $1.5 \mathrm{G}$ 太阳光照射下以最大功率点运行 $1000 \mathrm{~h}$ 后, 仍能保持初始 效率的 $90 \%$ 以上. 